\title{
John Dewey e a Escola Nova no Brasil
}

\begin{abstract}
Aluisio Pampolha Bevilaqua
Cientista político, bolsista do CNPq no Doutorado em Educação Brasileira da Universidade Federal do Ceará - UFC, Fortaleza, Brasil, membro do Conselho Editorial do Jornal INVERTA e do Conselho Editorial da Revista Ciência \& Luta de Classes do Centro de Educação Popular e Pesquisas Econômicas e Sociais - CEPPES.
\end{abstract}

\section{Resumo}

O presente artigo é uma reflexão sobre as ideias filosóficas e pedagógicas de John Dewey, presentes no Manifesto dos Pioneiros da Educação Nova no Brasil, lançado em 1932, em São Paulo. Seu ponto de partida é a hipótese de que o sistema pedagógico de Dewey, traduzido no Manifesto da Escola Nova, alterou substancialmente seu significado. Com base na dialética marxista, sugere que este fato resulta tanto da singularidade do processo histórico da sociedade brasileira, em especial do seu sistema educacional, quanto do próprio modelo teórico deste pedagogo. A pesquisa identifica as ideias e categorias filosóficas de Dewey, no escopo do Manifesto escolanovista, compara o significado das mesmas nos respectivos sistemas pedagógicos, apoiada na relação destes às bases empíricas dos quais são abstraídos e formas ideológicas que os mediatizam.

Palavras-Chave: Dewey, Filosofia, Manifesto dos Pioneiros, Brasil, Educação, História

\section{Resumen}

El actual trabajo es una reflección sobre las ideas filosóficas y pedagógicas de John Dewey presentes en el Manifesto dos Pioneiros da Educação Nova no Brasil (Manifiesto de los Pioneros de la Educación Nueva en Brasil) difundido en 1932, en São Paulo. Su punto de partida es la hipótesis de que el sistema pedagógico de Dewey, traducido en el Manifesto da Escola Nova, alteró sustancialmente su significado. Con base en la dialéctica marxista, sugiere que este hecho resulta tanto de la singularidad del proceso histórico de la sociedad brasileña, en especial su sistema educacional, cuanto del proprio modelo teórico de este pedagogo. La investigación identifica las ideas y categorías filosóficas de Dewey en el ámbito del Manifiesto escolanovista y compara su significado en los respectivos sistemas pedagógicos, apoyada en la relación de ellos con las bases empíricas de la cuales se extrayeron y formas ideológicas que los mediatizan.

Palabras llave: Dewey, Filosofía, Manifesto dos Pioneiros, Brasil, Educación, Historia 


\section{Abstract}

This article is a reflection on the philosophical and pedagogical ideas of John Dewey, these pioneers in the Manifesto of the New Education in Brazil, launched in 1932, in Sao Paulo. Its starting point is the assumption that Dewey's educational system, reflected in the Manifesto of the New School, substantially altered its meaning. Based on the Marxist dialectic suggests that this fact from both the uniqueness of the historical process of Brazilian society, in particular its educational system, but also of the theoretical model of teacher. It identifies the ideas and philosophical categories of Dewey, the scope of the Manifesto New School, compares the meaning of them in their education systems, draw on their relationship to empirical which are abstracted, and ideological forms that mediate.

Keywords: Dewey, Philosophy, Manifesto of the pioneers, Brazil, Education, History 


\section{Introdução}

$\mathrm{O}$ Manifesto dos Pioneiros da Educação Nova, lançado em 1932, marcou um momento de grande significado histórico na educação brasileira, condensando a insatisfação e crítica da jovem intelectualidade brasileira ao sistema educacional, inspiradas nas ideias filosóficas e pedagógicas mais avançadas da Europa e Estados Unidos, as concepções de John Dewey e Durkheim. A corrente formada por Fernando de Azevedo, Anísio Teixeira, Lourenço Filho, entre o total de 25 signatários do documento, com a sua análise da sociedade e proposta de diretrizes à reconstrução educacional do Brasil, no contexto histórico da denominada Revolução de 1930, levantou questões que até os dias atuais parecem vivas, quando se vive e pensa o sistema educacional brasileiro.

Do movimento resultaram conquistas históricas, tais como: o ensino laico, público e gratuito em todos os níveis, a responsabilidade do Estado e direito de todos os brasileiros; o fundo financeiro da educação; a estrutura escolar e o programa de ensino, de acordo com o desenvolvimento biopsicológico do indivíduo (pré-escolar, primeiro grau, segundo grau, e universidade); a diversificação do ensino no segundo grau entre humanas e profissional; o desenvolvimento da área de ciências exatas na universidade e a diversificação desta última em ensino e pesquisa.

Contudo, em termos do conteúdo pedagógico e da infraestrutura que viabiliza todo o aparelho educacional, parecem continuar presentes os problemas históricos levantados pelos pioneiros da Escola Nova e, justamente agora que começam a se implantar sistemas de avaliações escolares com base em critérios questionáveis, até que ponto deve-se retornar ao debate do problema educacional como um problema social ou como um problema meramente de qualidade de ensino? Se for este o debate, então estamos de volta à problematização tal qual partiu o movimento dos pioneiros da educação àquela época. E, se é assim, então cabe voltarmos de novo o olhar interessado para aquela experiência, reconstruindo-a intelectualmente com base no instrumental teórico atual e extrair as lições necessárias para os desafios educacionais atuais.

Com este propósito, o presente artigo tem por objetivo expor a pesquisa sobre o conteúdo das ideias pedagógicas no Manifesto dos Pioneiros da Educação Nova no Brasil e sugerir hipóteses do porque estas ideias não foram assimiladas no curso de nossa história educacional. A pesquisa que supõe este artigo toma por base o materialismo dialético, entendo-o como método capaz de explicar as ideias de um período histórico pelas contradições materiais deste período e as formas ideológicas com as quais os sujeitos sociais as compreenderam e levaram a cabo sua solução. Considerando ainda que este método se fundamenta em categorias históricas, entendendo que as categorias abstratas alteram seu conteúdo, na relação dialética com as transformações da realidade empírica, ele nos possibilita um olhar da rica totalidade de relações e determinações destas categorias sociais como concreto pensado e síntese de múltiplas determinações.

A pesquisa parte da seguinte hipótese: os principais obstáculos enfrentados pelas ideias de Dewey e o movimento da Escola Nova se localizam: primeiro, na alteração substancial de suas ideias no Manifesto de reconstrução educacional do Brasil, devido à particularidade do processo político conturbado de uma Revolução Liberal no Brasil, pela via prussiana, quase três séculos depois da primeira revolução liberal na Europa (1649-1658, na Inglaterra), um século e meio após a Revolução Francesa (1789), ou 


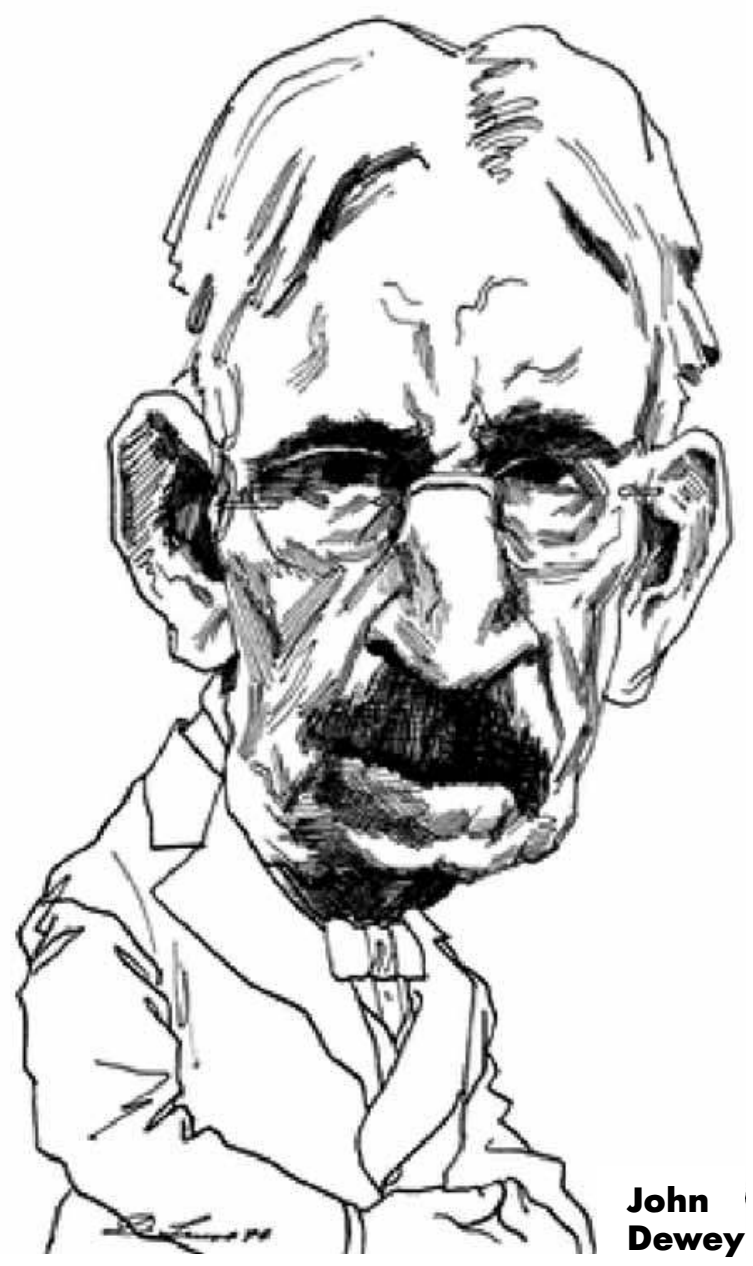

três quartos de século da Guerra Civil Americana (1861-1865); segundo, na raiz da base social e política do sistema educacional, dado o contexto histórico da formação da sociedade brasileira - a reforma e contra reforma religiosa na Europa - e das contradições internas entre a própria classe burguesa na luta contra o modo de produção feudal; terceira, na incompreensão dos escolanovistas das relações de unidade e contradição entre a superestrutura de domínio ideológico e o povo e as contradições do sistema filosófico e metodológico do pedagogo norte-americano John Dewey com esta realidade.

A título de finalização desta propedêutica, exige situar que o artigo se estrutura em cinco partes: a primeira introduz o tema e aponta o problema; a segunda situa historicamente o Manifesto dos Pioneiros e expõe as ideias contidas no mesmo; a terceira expõe as ideias de Dewey e as contextualiza no manifesto; a quarta conclui e sustenta a hipótese aqui apresentada; a quinta indica as referências bibliográficas. Importa ainda sugerir que talvez a maior consideração que tenha este trabalho seja despertar naqueles investigadores do tema e os que se preocupam com os rumos da educação brasileira a ideia que poderá conduzir o debate acadêmico ao encontro de dilemas cruciais da sociedade e que, cedo ou tarde, a solução do problema surgirá, como tem sempre surgido quando a universidade volta a respirar o mesmo ar que o povo respira. 


\section{0 Manifesto da Educação Nova no Brasil}

O Manifesto dos Pioneiros da Educação Nova no Brasil, cuja redação é de Fernando Azevedo, veio a público na Revista Educação - Órgão da Diretoria Geral de Ensino de São Paulo - a edição de janeiro/ fevereiro/ março de 1932, (FREITAS E BICCAS, 2009) cinco meses antes da contrarrevolução constitucionalista, entre 9 de julho a 4 de outubro, no estado que sedia a revista. (FERNANDES, 1975). Este acontecimento demonstra bem o período histórico vivido pelo Brasil, de efervescência social acumulada na sociedade civil, desde a Proclamação da República, em 1889, e que, a partir da primeira década do século passado, começa a vir à tona na cena política nacional. A expectativa formada entre os setores mais esclarecidos das classes sociais, em especial as camadas médias urbanas e o jovem movimento operário, passa a revelar o fracasso da Primeira República, denominada "Café-com-Leite", em que as oligarquias burguesas de São Paulo e Minas Gerais se sucediam no governo geral do país (FAUSTO, 1974, 1985).

A formação socioeconômica brasileira, distinta do processo histórico da Europa, Estados Unidos e demais países da América Latina, excetuando-se alguns países na região do Caribe (CARDOSO, 1988), em menos de 17 décadas, fez o que a Europa levou 17 séculos para fazer: transitar do escravismo ao capitalismo. Nas primeiras décadas do século passado, como em outros episódios da história brasileira, os setores mais ativos e instruídos do povo lutavam desesperadamente para se libertar da cultura do trabalho escravo e servil que se conformou pela matriz pedagógica eclesiástica que, do primeiro momento de sua antropogênese forçada - pela mecânica da inter- relação étnica - oculta sua trágica identidade (RIBEIRO, 1995), através dos mitos do "homem cordial", da "democracia racial" e das máscaras sociais, parodiando o velho continente europeu (CUNHA, 1975).

Enquanto isto, os contrastes das desigualdades sociais e regionais, herdadas das estruturas coloniais reconvertidas em capitalistas através dos choques adversos, da socialização das perdas (FURTADO, 1979) e na dialética da dependência (MARINI, 1976), pulsam nas aspirações nacionais das novas oligarquias burguesas dos principais centros do país, em contradição com as oligarquias tradicionais que se arrastam no interior, que, como mortos que se agarram aos vivos, exigem a ruptura definitiva, que a Primeira República não realizou. Rompendo-se o pacto oligárquico, entre São Paulo e Minas Gerais, abre-se a brecha para o protesto das camadas médias urbanas e do movimento operário contra o governo de Washington Luís. As oligarquias do Rio Grande do Sul e Paraíba unem-se à mineira, vão ao confronto eleitoral e a oligarquia paulista, apoiada em 17 estados, elege Júlio Prestes com mais de 80\% dos votos. Então, João Pessoa, vice-presidente da chapa derrotada de Getúlio Vargas, é assassinado e o curso da história muda. Desencadeia-se o putsch armado, cai a Primeira República e tem início a segunda República, em 1930 (FAUSTO, 1985).

O governo provisório de Getúlio Vargas procura legitimar o golpe e trabalha para cooptar as principais lideranças dos movimentos operário e popular e, sobretudo, os intelectuais; anuncia um conjunto de reformas com base nas demandas reprimidas na Primeira República. Entre os movimentos que eclodem na década precedente: o Tenentismo, Semana de Arte Moderna, está o da Educação (SCHAWARTZMAN, BOMENY, COSTA, 2000), que, em 1924, funda a Associação Brasileira de Educação, reunindo uma plêiade de intelectuais inspirados nas experiências 


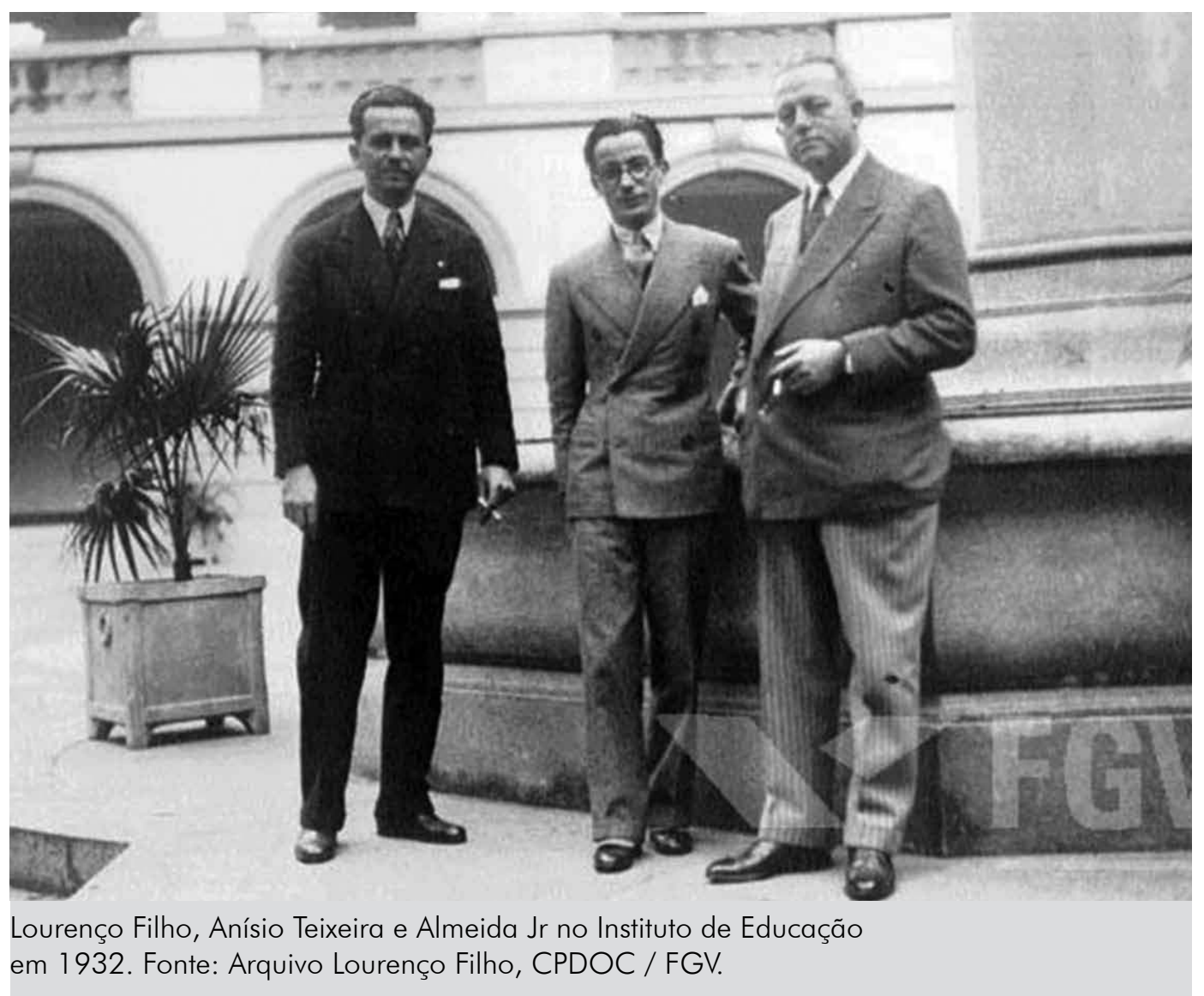

pedagógicas mais avançadas na Europa e Estados Unidos, que dirige as reformas educacionais em São Paulo, Ceará, Bahia e Distrito Federal (Rio de Janeiro). É a corrente pedagógica da Escola Nova, na qual estão à frente Lourenço Filho, Anísio Teixeira e Fernando Azevedo, dirigindo reformas para atender à demanda de mão de obra para o desenvolvimento industrial. Esta corrente se confronta diretamente com a herança do sistema educacional do país, presa à tradição escolástica do ensino tradicional (SAVIANI, 2008).

Mas esta herança não é tão simples derrotar, a tradição pedagógica eclesiástica foi iniciada em 1534, com o primeiro destacamento da Companhia de Jesus, liderado pelo Padre Manuel da Nóbrega. Ela moldou a vida cultural e intelectual da sociedade, estabeleceu o sistema simbólico de comunicação e formação através da dialética interétnica, que resulta na unidade sincrética e na diversidade semiótica de nossa formação social. Adaptou a pedagogia eclesiástica inventando o método Brasilis, este conformou o novo Ratio Studiorum (Ordem dos Estudos) do processo educacional que durante dois séculos consolidou o sistema linguístico e semântico, sustentou a unidade e desenvolveu a identidade do povo. Quando da expulsão dos jesuítas, em 1759, pelo Marquês de Pombal, são iniciadas as reformas no aparelho burocrático e educacional da Colônia inspiradas no iluminismo - o método pombalino - mas a estrutura material e humana intelectual deixada pelos jesuítas derrota estas reformas sobrepondo-se às aulas régias, mútuas e à lição das coisas. A Santa Aliança derrota a revolução francesa, a coroa volta a Portugal, o Brasil proclama a independência e se torna império. E, após aprovar em 1827 a Lei das Escolas de Primeiras Letras, os jesuítas regressam em 1843 e voltam a influenciar o sistema educacional do Brasil. 
Com a proibição do tráfico de escravos, em 1850, o movimento liberal volta à ofensiva, através da campanha abolicionista; o Imperador decreta a Lei da Terra, em 1853, cresce a urbanização - a industrialização e o comércio. Em 1884, Rui Barbosa pede reformas urgentes para o ensino primário, em seguida é decretada a libertação dos escravos e a economia da cana de açúcar vem abaixo, cai o império e nasce a República em 1889. Mas as reformas não aconteciam, no máximo mudanças cosméticas e inviabilizadas pela Igreja.

Contudo, a industrialização passa a demandar dos governos mão de obra qualificada e surgem reformas pontuais, em que se destaca um grupo de intelectuais que, em busca de ideias que pudessem resolver o problema da educação no país, vão aos Estados Unidos e tomam contato com as ideias de John Dewey, em especial Anísio Teixeira e Lourenço Filho. Assim surge o movimento escolanovista no Brasil. Em 1931, Getúlio Vargas, acompanhado do seu Ministro de Educação e Saúde, Francisco Campos, comparece à IV Conferência Nacional da Educação no Rio de Janeiro, solicita do conjunto dos educadores a elaboração de diretrizes para educação pública nacional. A proposta divide o movimento, Nóbrega da Cunha propõe que Fernando Azevedo escreva um manifesto guia; os católicos saem da $\mathrm{ABE}$ e fundam a Confederação Católica Brasileira de Educação. O documento veio a público, em março de 1932, sob o título A reconstrução educacional do Brasil - ao povo e ao governo e entra para a história após sua publicação em livro, pelo subtítulo adotado: "Manifesto dos Pioneiros da Educação Nova” (FREITAS E BICCAS, 2009). Embora eclético, é considerado um divisor de águas na história da educação do país.

Mas, quais são as ideias contidas do Manifesto dos Pioneiros da Educação Nova?

Exaltada por uns, criticada por outros, a composição teórica de Fernando de Azevedo não pode ser compreendida, nem explicada, fora do devido contexto econômico, social e político da sociedade e, muito menos, da situação particular do movimento da educação que se compunha de várias correntes de opiniões, naquele momento. Pois, se os uniam (os membros do movimento pela Escola Nova) a atividade profissional, a luta pelas reformas e como solucionar o problema; por outro, desuniam-nos os matizes de pensamentos sobre o problema educacional, as soluções para o mesmo e quem lideraria a execução desta. Com o manifesto, a divisão se simplifica: reformadores, liderados pelos escolanovistas, de um lado, e os conservadores católicos e integralistas, do outro.

Mas, se simplifica, por um lado, a divisão e facilita entender a correlação de forças que decidirá os rumos das reformas educacionais no Governo Vargas, por outro, complexifica a compreensão das ideias no Manifesto, considerando se tratar de composição teórica para unir correntes ideológicas díspares: liberais democráticos, nacionalistas, socialistas, comunistas, etc. Além disso, deve-se considerar a filiação durkheimiana do seu autor, que não entra em contradição tão antagônica com as ideias de Dewey, tendo em vista o escopo do Manifesto. Contudo, é possível identificar Dewey, Mannheim, Marx, Darwin ou Hegel, recheados de citações de teóricos da Escola dos Annales, o elitista e autoritário Alberto Torres (SAVIANI, 2008) e até mesmo paráfrases a Lênin.

Em síntese, as ideias contidas no Manifesto são as seguintes: a) Na introdução, apontava-se para a necessidade de uma reforma educacional ampla e, embora se associasse esta reforma a outras de caráter econômico e social, não se estabelecia uma relação de unidade entre todos os elementos a serem reformados. Ainda na própria introdução, indicava-se a ausência, no Brasil, de uma filosofia da educação e de 
uma técnica educacional (aplicação de métodos científicos à educação). b) No item Movimento de Renovação Nacional, se criticava a escola como instituição a se manter segregada do todo social e demandava-se uma atualização/revisão desta prática. c) No item Finalidades da Educação, sobressaía o ideal democrático de formação do cidadão, mas segundo uma ótica burguesa individualista. d) No item Valores Mutáveis e Valores Permanentes, eram destacados como valores permanentes, o trabalho - sem, no entanto, questionar seu processo de divisão na sociedade capitalista - o espírito de renúncia, disciplina, justiça, consciência social e respeito ao ser humano. e) No item O Estado em Face da Educação, defendia-se a escola pública, gratuita, leiga, obrigatória e a coeducação. f) No item $A$ Função Educacional, propunha-se, além da autonomia e descentralização da função, sua unidade com vistas a atender às diferentes fases do desenvolvimento do educando. g) No item O Processo Educativo, Conceito e Fundamentos da Educação Nova, algumas premissas escolanovistas eram enfatizadas, tais como a aprendizagem ativa e a criança como centro de tal processo. h) No item Plano de Reconstrução Nacional, reforçava-se além do ensino ativo e criativo, uma continuidade de articulação das reformas educacionais, fato até então impensável em termos brasileiros, bem como a produção cultural pelas universidades. i) Os itens $A$ Unidade de Formação dos Professores e a Unidade de Espirito, O Papel da Escola na Vida e sua Função Social e A Democracia: Um Programa de longos deveres apontavam para uma educação cujo propósito seria dar ao povo consciência de si mesmo. A ingenuidade se centrava no fato de se crer a educação com poderes de revolucionar a sociedade.j) Em 42 páginas, desdobravam-se na defesa da escola pública e o direito de todas as classes à educação integral. Rogava-se por uma ação objetiva do Estado no sentido de ir eliminando os obstáculos impostos às classes menos favorecidas, referentes às oportunidades educacionais, tornando a obrigatoriedade escolar um instrumento para extinguir privilégios classistas.

\section{As ideias de John Dewey e o Manifesto}

As ideias pedagógicas de John Dewey, denominadas de Escola Nova, surgem das suas reflexões sobre o problema educacional nos Estados Unidos no início do século $\mathrm{XX}$, período em que a estrutura socioeconômica capitalista deste país completa a transição ao imperialismo. A raiz filosófica da pedagogia liberal remonta à ruptura no interior da doutrina liberal, de Stuart Mill e seu ex-preceptor Jeremy Bentham, a quem seu pai James Stuart era seguidor e continuador. Esta se localiza na definição do caráter público ou privado da educação, cuja grande dificuldade residia, sobretudo, no fundo filosófico da mesma: o debate de Hobbes, Locke e Rousseau (XVII/ XVIII), em torno do caráter divino ou da natureza humana. Com base nestas respostas ergueram-se as teorias de formas de constituição e governo do que se chamou Estado Moderno (MACPHERSON, 1979).

Hobbes respondeu que a natureza humana era "individualista, possessiva e mesquinha”, em estado de liberdade era o homem lobo do homem, e propõe o Leviatã - a educação sobre o controle do Estado; Locke respondeu que o ser humano era como "uma folha de papel em branco", portanto, o estado de liberdade é o governo democrático misto, o Estado não interviria na educação que seria individual e privada; Rousseau respondeu, ao revés de Hobbes, que a natureza humana era pura, a tese do "bom selvagem", o estado de liberdade e a educação, o mais livre possível, para que a 
inclinação pura dos Emílios se desenvolva; Bentham defendia que "o indivíduo não entrava totalmente equipado na vida social", sua tendência era fazer tudo que dava prazer e o Estado deveria ser um instrumento útil à realização da individualidade humana inclusive na educação (DUMONT, 1985).

Mill, no século XVIII, vendo os efeitos da revolução industrial sobre o povo, embora defendesse a liberdade individual e o utilitarismo, amplia este conceito até a assistência social e a educação, ao contrário do que defendiam o seu pai e Bentham (MACPHERSON, 1979). Hume, no entanto, continua a defender a tese de Locke, e seu estudo empirista sobre a mente humana leva ao psicologismo, que, na Alemanha, dá lugar ao agnosticismo de Kant, ao idealismo de Hegel e ao irracionalismo de Husserl e Schopenhauer. Esta posição divide o liberalismo, constituindo duas vertentes: o liberalismo social de Mill e o liberalismo possessivo de Bentham.

Este debate dentro da doutrina liberal se prolonga e chega aos Estados Unidos no século XIX, através de Chauncy Wright, mas logo é rejeitado pela classe dominante. Contudo, deixa raízes que mais tarde retornam com mais força. Esta é a origem do problema pedagógico que Dewey enfrentaria no seu tempo: educação repressiva ou educação livre, educação privada ou pública? Mas este tempo não estava distante, os EUA passaram da economia agrícola à industrial, receberam fortes correntes migratórias, além da herança escravocrata. Dewey nasce em Berrington, em 1859, cidade ainda vivendo o intimismo comunitário do interior. Dois anos depois estoura a Guerra Civil (1861-1863) entre o sul escravocrata e o norte industrial, que elimina $600 \mathrm{mil}$ norte-americanos e deixa como herança a segregação racial-social. A Ku Klux Klan foi criada em Nashville, em 1867, para impedir que os negros se tornassem livres.

A crise econômica que se manifesta logo após a guerra civil (MARX, 1996) abate ainda mais o moral do povo norte-americano, que ainda chora os mortos e, diante deste quadro depressivo social, um grupo de jovens intelectuais de Cambridge resolve mudar a situação e formam o Clube da Metafísica, em 1870; acreditam que o problema era o autoritarismo da educação, presa à moral religiosa do protestantismo e passam a defender as ideias que o "destino das pessoas está em suas próprias mãos" (Uma releitura da Doutrina do Destino Manifesto). Neste grupo de jovens estão os dois principais personagens que vão criar a filosofia americana do Pragmatismo: Charles Peirce - que defende a tese da semiótica, próxima das interpretações de Hume, Kant e Berkeley - e William James, cujas teses se aproximam do utilitarismo de Stuart Mill, Darwin e Spencer - o positivismo.

Dewey, no entanto, em seu ceticismo de estudante conhece o hegelianismo, o darwinismo, até chegar ao pragmatismo de Pierce e James; o primeiro, considerado fundador de fato do pragmatismo. Mas, até chegar a representante deste pensamento filosófico liberal, realizou uma longa marcha de ativismo intelectual e social, escrevendo em revistas, lecionando, participando dos movimentos democráticos e libertários liberais até ser reconhecido por sua obra, sendo profundamente sensibilizado pelas agudas crises que passa viver o seu país e o mundo.

Em seu livro Experiência e Natureza, faz uma forte defesa do método experimental. Inicia discutindo justamente o método, respondendo ao dilema kantiano da cognoscibilidade ou não da verdade objetiva e responde, como Hegel, que é possível, que a aplicação do método experimental pelas ciências tem chegado até mesmo ao coração da natureza. Em seguida, passa à discussão sobre o método experimental e a filosofia, argumentando que ela toma de empréstimo as abstrações que resultam das experiências na ciência natural e as utiliza para desacreditar o método científico e 
que, ao invés de aplicá-lo, forja contradições, que resultam muito mais das crenças e preconceitos. Logo depois, aborda a questão da história e do conhecimento humano, chegando à assertiva que a linguagem é que diferencia o homem dos outros animais, pois ela supõe significados, logo a interação social, marcando a passagem da natureza à cultura, o uso da mimesis, os símbolos, ou o fenômeno da comunicação que só acontece em sociedade. Continua nas partes seguintes debatendo a relação entre psicologia e biologia, defendendo que a ideia de evolução mostra a qualidade do movimento da natureza biológica do homem (DEWEY, 1926).

Em seu trabalho A Influência do Darwinismo na Filosofia, (DEWEY, 1910) o autor aborda a relação entre homem/natureza, abstraindo a expressão mais simples: vida/ natureza, se apoiando na fusão da teoria de Galileu e de Darwin, sugerindo a ideia de que experiência e vida guardam o mesmo significado, pois é resultado da própria experiência da natureza. Identifica no movimento de inter-relação dos corpos e organismos o livre movimento para sua evolução natural, o que o leva a concluir mais tarde em seu trabalho Experiência e Educação (DEWEY, 1997) e a reafirmar em seu livro que condensa todo o seu trabalho em pedagogia, Democracia e Educação (DEWEY, 2001), que a liberdade, o liberalismo, é condição natural para o desenvolvimento da vida. Desta sua concepção da evolução, fundamenta o critério biológico como base fundamental contra todos os tipos de preconceitos. A vida em sua condição natural e mais primária demonstra que a evolução da espécie humana biologicamente necessita da liberdade de movimento para se desenvolver tanto física quanto intelectualmente, portanto, da educação como prática de experiência e liberdade.

Embora sustente o método experimental, sua análise filosófica recorre sempre ao método histórico de Hegel para entender a dialética da origem das contradições, vendo como algo que se apresenta harmônica inicialmente e a partir do seu movimento histórico vai se desdobrando em contradições; daí sua tese de que os problemas em teoria são reais e que a solução está em se afastar até o ponto de harmonia entre seus aspectos contraditórios principais e depois reconstruir o problema, visão que vai desenvolver ao abordar o problema da criança e o programa escolar. O que é mais importante é que a nova visão da vida, a partir do seu método de solucionar os problemas - a dialética hegeliana aplicada à história - vai constituir as bases da sua Pedagogia da Educação, como expressão natural da vida da espécie humana ou sua natureza livre de movimento, ou seja, sua condição liberal e democrática, como fundamento natural da organização social - aqui sua posição é aristotélica: o homem como ser social (DEWEY, 1997).

No seu livro Democracia e Educação, ele identifica a educação como fenômeno natural de perpetuação e renovação do conhecimento de um grupo social. Remonta a sua condição natural de identidade com a vida familiar e do grupo social, antes de se desdobrar na sociedade complexa como atividade separada da vida familiar ou comunidade ou grupo social. Neste livro, é visível a base centrada no empréstimo da teoria dos corpos de Galileu, Newton, do racionalismo de Descartes, toma-se de empréstimo a geometria euclidiana, e une ao método experimental de Bacon, sua identificação da energia como fenômeno que interage com os demais elementos da natureza. E fundamenta a diferença da espécie humana pela capacidade de desenvolver a comunicação e a linguagem dos símbolos (Pierce) e evoluir em liberdade (democracia) e na lógica da seleção natural das espécies, que no caso humano é a inteligência, isto é, sua condição 
lógica e teleológica (James) de inventar a cultura artificial e dirigir suas ações por ela, observando e controlando sua experiência da sociedade transmitida (DEWEY,2001).

A educação como hoje existe é um acúmulo de experiências da sociedade, transmitida através do processo natural da vida e esta também como experiência, cujo significado muda a cada período da história (Hegel). Portanto, a educação, como a verdade, se julga pela pragma (ação), a experiência, e sua evolução decorre da capacidade natural de liberdade, de experimentar e, através da experiência, reconstruir os valores, desenvolvendo novos critérios da estrutura da sociedade e acrescentando novos valores sobre o critério da própria experiência. Portanto, é na ideia de que tudo que conserva a vida (aqui é hobbesiano) é útil e, portanto, seu encontro com o utilitarismo de Stuart Mill, mas em regime de liberdade, que é uma condição natural da humanidade. $\mathrm{O}$ impulso das necessidades vitais (Darwin) direciona o autor para a experiência. E a construção racional da sua satisfação através da imaginação (teleologia), é psicológica no sentido comportamental, em relação de interação ao meio (behaviorismo, James), explica o universo simbólico de identidade significante da mesma e sua satisfação à ideia do bom, do justo, quase no sentido benthiano, que escapa pela materialidade da experiência. Vale mais o hedonismo (Epicuro) e o materialismo (Marx) que a ideia de Divino (puritanismo) (DEWEY, 2001).

Assim, pode-se entender suas ideias sobre educação, que poderiam ser traduzidas em : vida $=$ movimento $/$ evolução $=$ experiência $/$ cultura $=$ transmissão da experiência $/$ cultura $=$ vida acumulada $=$ experiência ou cultura acumulada $=$ perpetuação da espécie ou grupo social, seus costumes, conhecimentos e regras sociais.

É assim que em seu trabalho Criança e o Programa Escolar, parte da contradição criança/escola (programa), abstrai para criança/adulto, depois vida/educação. Neste ponto aplica o método da digressão histórica até chegar ao momento em que vida e educação estavam em harmonia e significavam uma única e mesma coisa, isto é, na origem da relação homem/natureza. A partir daí, faz o percurso de volta e identifica o problema na passagem da educação familiar para educação escolar/sociedade. Então, aplica o método biológico e psicológico, definindo biopsicologicamente o universo infantil e o universo do adulto, na relação indivíduo/sociedade, reconstituindo o problema sob nova base. Observa que a contradição vida/experiência não é uma contradição antagônica, mas inteiração dialética, na noção do ser e o não ser presente no devir, no movimento da vida. Ao reduzir tudo à experiência da espécie humana, conclui-se que: a) a contradição criança/programa escolar são dois momentos da experiência humana, o momento infantil e o momento adulto, que se resolve pela contradição educação familiar/educação na sociedade; b) Não sendo antagônica, implica tão somente numa contradição de grau (quantidade), pois se trata de uma relação entre a mesma espécie, precisamente, a espécie humana; c) Localiza o momento não contraditório na vida da espécie: a casa, a vida em família ou comunidade, momento em que vida e a educação significavam a mesma coisa, não havia dissociação. d) Reconstrói o problema diante da sociedade concreta e vê na escola o artifício humano encontrado para solucionar a contradição. e) Fazendo isto, entende que é a sociedade que deve reestruturar a escola para que ela integre a criança na mesma.f) Nestes termos, se a criança é igual à sociedade e esta é igual à escola, então escola é igual à criança, portanto, é na criança que está o início e o fim da sociedade, por conseguinte, a escola e seus programas de ensino devem atender aos interesses das crianças. g) Assim é que na escola está o início, o meio e o fim da sociedade: a criança. Ao invés da criança ir à sociedade é 
a sociedade que vem até a criança pela ambiência e a reconstrução do seu programa escolar, tendo por início e fim a criança.

Com relação à reestruturação, o princípio é o interesse da criança, é ela quem determina o processo de reconstrução do programa. Partindo deste fato, considerando que o mundo da criança é integral e unitário; considerando que seus interesses ou tendências implicam em estágios ou etapas daquilo que já está desenvolvido na sociedade em termos de abstrações, verdades, regras, lógica: deve-se a partir deste interesse da criança por uma disciplina ou matéria escolar, passar todo o conteúdo desta matéria escolar, utilizando-se da sistematização lógica e racional. A todo este processo deve-se entender como interação de experiência da criança à experiência total da sociedade e da espécie humana, através da experiência artificial da escola, em termos de ambiência instrumental, equipamentos técnicos e intelectuais.

A contradição professor/aluno se resolve pelo papel do educador de dirigir a reconstrução do programa, a ambiência escolar e a transmissão da cultura, utilizando os recursos técnicos e espaços para que o interesse da criança seja atendido de forma lógica e psicológica. Para isto, deve diferenciar os critérios na interpretação do material escolar e do material experiencial, para que sua direção não expanda o pensamento da criança, em torno de tendências equivocadas e que se choquem contra a vida da sociedade. Neste caso, a experiência acumulada na sociedade permite o critério sistemático e método científico para que a criança expanda o seu pensamento; daí, a importância das matérias de estudo não serem fragmentadas, mas ensinadas na totalidade, permitindo à criança se integrar diretamente na sociedade, por seus interesses manifestados, transformados em programas, realizando o processo de educação útil à sociedade.

Se a criança é um organismo vivo em evolução para um organismo desenvolvido adulto em sociedade; se a sociedade é um processo natural da experiência humana; se a liberdade e harmonia da vida e educação estão separadas na sociedade atual através da escola, então a escola deve ser reconstruída com liberdade e cooperação reproduzindo o ambiente natural, artificialmente, para que as tendências democráticas da natureza humana da criança se desenvolvam, logo, somente em uma Escola Nova este objetivo será alcançado.

Assim, a própria educação é um direito biológico da criança e a democracia, a liberdade da vida escolar, condição ou ambiente necessário como na natureza, diferenciando o ser humano por suas capacidades biopsicológicas, produzindo uma seleção natural pelas aptidões e capacidades desenvolvidas. Contudo, somente nestas condições, de democracia e liberdade da escola, o estado e o governo podem assumir a educação pública, dirigida à reprodução da vida social, e, neste caso, torna-se um direito de todos; logo, pública e gratuita e descentralizada para atender as particularidades das comunidades e chegar à individualidade da criança.

Considerando ainda que a relação indivíduo/sociedade é composta por elementos dinâmicos que se (inter) relacionam, interagem e interpenetram; a experiência educacional é um processo perpétuo de reconstrução dos conhecimentos e a invenção de novos, atuando sobre a sociedade e garantindo a continuidade e o desenvolvimento da vida material e intelectual, logo, a renovação da vida cultural e dos valores sociais constantes. Então aqui se chega ao ponto de definir que tipo de ambiência escolar é capaz de reproduzir a vida social. A definição é: a escola baseada na própria condição primária da existência humana quando educação era igual à vida: o trabalho. Portanto, é a escola voltada ao trabalho, a melhor ambiência para 
desenvolver a experiência de cooperação, disciplina, individualidade e personalidade útil do indivíduo para a sociedade.

Desta forma, chega-se ao problema final: quais são as ideias de John Dewey no Manifesto dos Pioneiros da Educação Nova no Brasil? A resposta é simples: quase todas. As categorias dhurkeimianas utilizadas por Fernando Azevedo não são antagônicas à pedagogia instrumental de John Dewey, o que se pode assinalar são as partes do Manifesto onde seu pensamento é mais visível, tais como: a noção de vida e ideal que devem conformar-se aos educandos, entre ideias abstratas e absolutas e ideias concretas e relativas; as ideias sempre variam de acordo com a estrutura e tendências sociais da época - a educação e o pensamento pedagógico; a oposição das ideias da Escola Nova às ideias da escola tradicional; o critério biológico ao econômico para o direito de todos os indivíduos à educação, segundo as aptidões e, superando a educação de classe; a hierarquia democrática pela hierarquia das capacidades, ou seja, a meritocracia; o objetivo da educação nova "é desenvolver os meios de ação duráveis com o fim de dirigir o desenvolvimento natural e integral do ser humano, em cada uma das etapas do seu crescimento, de acordo com certa concepção do mundo", o argumento de que os diferentes conceitos de vida decorrem das diferenças de classes e da noção de socialmente útil e que, do ponto de vista pragmático, a educação serve aos interesses do indivíduo, no vínculo da escola como meio social.

Em síntese: educação como guia em torno de um ideal de vida, caracterizado pela organização da sociedade; indivíduo como possuidor de suas 'aptidões naturais', independente de sua ordem econômica e/ou social; trabalho como a melhor maneira de estudar a realidade em si e este em si mesmo; respeito à personalidade humana, como fim em si mesmo; a educação como dever do Estado, mas as instituições privadas tendo total liberdade; acredita que a educação é capaz de abarcar as mudanças que passam a ocorrer na sociedade; encara a educação sob o prisma psicológico; seus princípios básicos são: laicidade, gratuidade, obrigatoriedade e coeducação; propõe que todas as crianças (de sete a quinze anos) sejam confiadas à escola pública, com uma educação comum a todas; defende a autonomia técnica, administrativa e econômica da escola pública, além de uma educação descentralizada; defende que o professorado deveria ter uma formação universitária independente do nível que lecione; acredita que o 'ponto nevrálgico' do problema educacional estava na escola secundária e que, apenas através da educação, os princípios democráticos poderiam vir a ser legitimados.

\section{Conclusão: por que não deu certo?}

Como foi enunciado na introdução deste artigo, seu propósito é sustentar a hipótese que as ideias de Dewey sofreram uma alteração substancial no Manifesto de reconstrução educacional do Brasil e que esta suposição se sustentava com base em três outras hipóteses acerca das dificuldades enfrentadas pelos escolanovistas e as ideias do pedagogo norte-americano, que eram: a) a particularidade da Revolução Liberal no Brasil, pela via prussiana, quase três séculos depois da primeira revolução liberal na Inglaterra, um século e meio após a Revolução Francesa, ou três quartos de século da Guerra Civil Americana; b) a base social e política do sistema educacional, dado o contexto histórico da formação da sociedade brasileira - a reforma e contrarreforma religiosa na Europa - e das contradições internas entre a própria classe burguesa na luta contra o modo de produção feudal e; c) na incompreensão dos escolanovistas 
das relações de unidade e contradição entre a superestrutura de domínio ideológico e o povo e nas contradições do sistema filosófico e metodológico do pedagogo norte-americano John Dewey, com esta realidade.

Como se pode concluir do estudo apresentado, a deformação não consiste em adulteração das ideias de Dewey, em relação ao seu modelo pedagógico, mas em relação ao sentido histórico da aplicação destas ideias a uma formação socioeconômica díspare dos Estados Unidos. Primeiro, porque o que se colocava para o Brasil, em 1930, não era saber que tipo de pedagogia liberal era mais adequada e útil para os indivíduos, mas, sobretudo, que programa de reformas poderia ser realizado na educação e em outras esferas do poder público, que facilitasse e assegurasse a passagem da hegemonia política das mãos das velhas oligarquias para as novas oligarquias burguesas; todas as ideias contidas no Manifesto, por mais coerentes que estivessem com o sistema pedagógico de Dewey, perderiam seu sentido histórico educacional, portanto, alterando substancialmente o seu sentido. Segundo, porque historicamente e culturalmente a formação brasileira é totalmente contrária à prática liberal e não se pode considerar crível imaginar instituir uma prática social de um dia para outro, se tomamos de empréstimo o próprio critério de Dewey, da experiência. No Brasil, a experiência acumulada em cerca de cinco séculos não é mais que uma amálgama de práticas, escravocrata, feudal e de capitalismo oligárquico mesmo após a passagem da subordinação formal à subordinação real do trabalho ao capital. Aqui, vale apenas lembrar o trabalho de Schwarz, sobre as ideias fora de lugar.

Em relação à segunda hipótese, esta pesquisa nos permite sustentar que o papel conferido à Companhia de Jesus, na formação da estrutura educacional do país, por um lado, decorre da posição da nobreza feudal portuguesa no processo de contrarreforma à reforma religiosa e ao liberalismo, de acumular forças para o confronto na Europa até a derrota da Revolução Francesa pela Santa Aliança. Por outro lado, o Pacto Colonial entre o capital mercantil e a nobreza feudal e Igreja, que se sustenta na contradição entre este setor da burguesia contra o capital industrial e o capital usurário, aliados aos reformistas. Portanto, são esses os dois fatores que criam as condições para Igreja Católica se constituir em força social e política na sociedade, capaz de impedir qualquer reforma mais avançada no sistema educacional, pois é a partir do trabalho dos jesuítas que a Igreja Católica estendeu raízes de domínio ideológico por sobre a maior parte do povo brasileiro.

Nestes termos, o singular processo de conformação do sistema educacional brasileiro, no curso de dois séculos e meio seguidos pelo trabalho dos jesuítas - no espírito de uma organização militar de combate a qualquer cultura fora dos paradigmas eclesiásticos - mais que um sistema educacional, forjou um sistema de unidade linguística e identidade nacional através da interação étnica e simbólica impossível de ser alterada por quaisquer método, leis, ou ideias que sejam. Isto está além das manobras políticas da Igreja para impedir a nomeação de um membro da Escola Nova ao governo, tal qual ocorreu no ministério de Capanema no Estado Novo. Aqui, há algo mais, trata-se de raízes sociais, "o Brasil profundo" do qual falou o poeta Carlos Drummond de Andrade.

Finalmente, podemos concluir deste trabalho que o problema em relação às ideias pedagógicas de Dewey não reside tão somente na alteração substancial de suas ideias aplicadas numa conjuntura e realidade histórica distinta, ou ainda resultante da particularidade histórica do sistema educacional brasileiro, há que atentar aqui para o aspecto 
mais importante e que está relacionado às próprias ideias do seu sistema educacional. E este problema reside justamente em que nenhum modelo educacional, político, ou cultural, pode ser aplicado diretamente em uma realidade histórica particular. Isto é uma concepção mecânica e pobre do ponto de vista intelectual; naturalmente não quer dizer que não devemos copiar as coisas boas, ou ao menos tentar adaptá-las à realidade nacional, mas tendo em vista as particularidades históricas. Contudo, a abstração do liberal John Dewey, por maior que seja sua idealização de liberdade, justiça e humanidade, não é capaz de perceber que todo o idealismo rousseauniano, e o evolucionismo darwiniano, toda a dialética hegeliana, não se sustentam diante de uma sociedade de classes, que se organiza para exploração do homem pelo homem. O idealismo, como sistema filosófico, mesmo em sua versão pragmática e utilitária, para além do discurso, serve apenas para iludir as massas, pois na prática não se realiza a prova mais contundente deste fato: que mesmo nos Estados Unidos suas ideias não vingaram. Isto quer dizer que devemos abandonar os ideais de uma escola igualitária, socializada e capaz de formar o homem novo? Se nossa resposta for não, então lutemos por eles!.

\section{Bibliografia}

ABBAGNANO, Nicola. História da Filosofia. Vol. XI, Editora Presença, Lisboa: 1970. ANDERSON, Perry. Linhagens do Estado Absolutista. Porto: Edições Afrontamento, 1984.

AZEVEDO, Fernando. A Cultura Brasileira. Introdução ao Estudo da Cultura no Brasil. Tomo III, Melhoramentos, 3º ed., São Paulo: 1958.

. A Reconstrução Educacional do Brasil. Ao povo e ao governo. Manifesto dos

Pioneiros da Educação Nova. Companhia Editora Nacional, São Paulo: 1932.

BOBBIO, Norberto. A teoria das formas de governo. Brasília: 10a Edição, Ed. UNB, 1997.

BRAVO, Carlos Ramiro. El pensamiento de Jeremy Benthan. Colômbia, Revista de Ciências Humanas No. 20, 2000.

CUNHA, Euclides da. Contrastes e Confrontos. Rio de Janeiro: Record, 1975. DEWEY, John. The Influence of Darwin on Philosophy And Other Essays in Contemporary Thought. New York: Henry Holt and Company, 1910.

. Experience and Education. New York: First Touchstone Edition, 1997

Democracy and Education The Pennsylvania State University. A Penn State

Electronic Classics Series Publication: Pennsylvania, 2001.

. Experience and Nature, Open Court and The Monist. Chicago, 1926.

. Vida e Sociedade. 10 o ed. Rio de Janeiro: Melhoramentos, 1978.

DUMONT, Louis. O Individualismo - uma perspectiva antropológica da ideologia moderna. Rio de Janeiro Ed. Rocco, 1985.

DURKHEIM, Emile. Educação e Sociologia. 5o ed. São Paulo: Melhoramentos, (s/d). FREITAS, Marcos Cezar de, BICCAS, Maurilane de Souza. História Social da Educação no Brasil (1926-1996). São Paulo: Cortez, 2009.

GIROUX, Henry. Escola Crítica e Política Cultural. São Paulo: Cortez, 1987.

GUZMÁN, Maylín Frías; RIVERA, Zoia. El pragmatismo en la bibliotecología cubana de la República, disponível em: http://scielo.sld.cu/pdf/aci/v17n6/aci03608.pdf, acesso 03/12/2009. 
HEGEL, G. W. F. Ciencia de la Lógica. 5o ed. Buenos Aires: Ediciones Solar, 1982. . Fenomenologia do Espírito. Vol. 1 e 2, Petrópolis: Vozes, 1988.

KANT, Immanuel. Crítica da Razão Pura. 2o ed. Lisboa: Fundação Calouste Gulbenkian, 1989.

LENIN, V. I. Cuadernos Filosoficos. Tomo XXIX, Muscú: Progresso, 1986.

HOLANDA, Sérgio Buarque de. Raízes do Brasil. 17a ed. Rio de Janeiro: José Olímpio, 1984.

JONES. Elizabeth. E Por Falar Em John Dewey. Perspectiva, r. CED, Florianópolis, jul/dez, 1989.

LANCASTER, Lane W. Master of Political Thought. Hegel to Dewey. London: George G. Harrap \& Co. Ltd., 1969.

MACPHERSON, C. B. A teoria politica do individualismo possessivo. Rio de Janeiro: Paz e Terra, 1979.

MARX, Karl e ENGELS, Friedrich. La Ideologia Alemana. Buenos Aires: Ediciones PueblosUnidos, 1973.

. The Capital. Vol. I, Collected Works, Volume 35. London: Lawrence \& Wishart, 1996.

. Contribuição Para Crítica da Economia Política. 5a ed. Lisboa: Estampa, 1977.

MILL, Stuart. Princípio de Economia Política. São Paulo: Nova Cultural, 1986.

. Sobre a Liberdade. Edição Eletrônica, Instituto Liberal do Rio de Janeiro, 2003.

NAGLE, Jorge. Educação e Sociedade Na Primeira República. 2a . ed. Rio de Janeiro: DP\&A, 2001.

RIBEIRO, Darcy. O Povo Brasileiro. Formação e o Sentido do Brasil. São Paulo: Companhia das Letras, 1995.

SAVIANI, Demerval. A Pedagogia no Brasil. História e Teoria. Campinas: Autores Associados, 2008.

SCHWARZ, Roberto. Ao Vencedor as Batatas. $3^{\mathrm{a}}$. ed. São Paulo: Livraria Duas Cidades, 1988.

SCHWARZMAN, Simon, BOMENY, Helena Maria Bousquet, COSTA, Vanda Maria Ribeiro. Tempos de Capanema. São Paulo: Paz e Terra; Rio: Fundação Getúlio Vargas, 2000.

. História das Ideias Pedagógicas no Brasil. Campinas: Autores Associados, 2007. SUCHODOLSKI, Bogdan. Teoria Marxista da Educação. Vol. III. Lisboa: Editora Estampa, 1976.

VOLPE, Galvano Della. Rousseau y Marx. Roma: Ediciones Martinez Roca S. A., 1972. 